Article

\title{
Supplementation-Dependent Effects of Vegetable Oils with Varying Fatty Acid Compositions on Anthropometric and Biochemical Parameters in Obese Women
}

\author{
Luciene Oliveira-de-Lira ${ }^{1, *(1)}$, Eduila Maria Couto Santos ${ }^{2}$, Raphael Fabrício de Souza ${ }^{3}$, \\ Rhowena Jane Barbosa Matos ${ }^{2}$, Matilde Cesiana da Silva ${ }^{2}$, Lisiane dos Santos Oliveira ${ }^{2}$, \\ Taís Galdêncio do Nascimento ${ }^{1}$, Paulo Artur de Lara Schinda Schemly ${ }^{3}$ and \\ Sandra Lopes de Souza ${ }^{1}$ \\ 1 PostGraduate Program, Department of Nutrition, Federal University of Pernambuco, \\ Pernambuco 50670-901, Brazil; tais_galdencio96@hotmail.com (T.G.d.N.); sanlopesufpe@gmail.com (S.L.d.S.) \\ 2 Academic Center of Vitoria de Santo Antão, Federal University of Pernambuco, Pernambuco 55608-680, \\ Brazil; eduila@hotmail.com (E.M.C.S.); rhowenajane@gmail.com (R.J.B.M.); \\ matildecesiana@hotmail.com (M.C.d.S.); lisianenutricao@yahoo.com.br (L.d.S.O.) \\ 3 Department of Physical Education, Federal University of Sergipe-UFS, São Cristovão, \\ Sergipe 49100-000, Brazil; raphaelctba20@hotmail.com (R.F.d.S.); pshinda@bol.com.br (P.A.d.L.S.S.) \\ * Correspondence: oliveira.de.lira.1@gmail.com; Tel.: +55-081-2126-8463
}

Received: 6 July 2018; Accepted: 18 July 2018; Published: 20 July 2018

\begin{abstract}
Fatty acid (FA) composition is a determinant of the physiological effects of dietary oils. This study investigated the effects of vegetable oil supplementation with different FA compositions on anthropometric and biochemical parameters in obese women on a hypocaloric diet with lifestyle modifications. Seventy-five women (body mass index, BMI, 30-39.9kg $/ \mathrm{m}^{2}$ ) were randomized based on 8-week oil supplementation into four experimental groups: the coconut oil group (CoG, $n=18)$, the safflower oil group (SafG, $n=19$ ), the chia oil group (ChG, $n=19$ ), and the soybean oil placebo group (PG, $n=19)$. Pre- and post-supplementation weight, anthropometric parameters, and body fat $(\% \mathrm{BF})$, and lean mass percentages (\%LM) were evaluated, along with biochemical parameters related to lipid and glycidemic profiles. In the anthropometric evaluation, the CoG showed greater weight loss $(\Delta \%=-8.54 \pm 2.38)$, and reduced BMI (absolute variation, $\Delta$ abs $=-2.86 \pm 0.79$ ), waist circumference $(\Delta \mathrm{abs}=-6.61 \pm 0.85)$, waist-to-height ratio $(\Delta \mathrm{abs}=-0.041 \pm 0.006)$, conicity index $(\Delta \mathrm{abs}=-0.03 \pm 0.016)$, and $\% \mathrm{BF}(\Delta \mathrm{abs}=-2.78 \pm 0.46)$, but increased $\% \mathrm{LM}(\Delta \mathrm{abs}=2.61 \pm 1.40)$ $(p<0.001)$. Moreover, the CoG showed a higher reduction in biochemical parameters of glycemia $(\Delta \mathrm{abs}=-24.71 \pm 8.13)$ and glycated hemoglobin $(\Delta \mathrm{abs}=-0.86 \pm 0.28)(p<0.001)$. The ChG showed a higher reduction in cholesterol $(\Delta \mathrm{abs}=-45.36 \pm 0.94)$, low-density lipoprotein cholesterol (LDLc; $\Delta$ abs $=-42.53 \pm 22.65)$, and triglycerides $(\Delta \mathrm{abs}=-49.74 \pm 26.3)$, but an increase in high-density lipoprotein cholesterol (HDLc; abs $=3.73 \pm 1.24, p=0.007$ ). Coconut oil had a more pronounced effect on abdominal adiposity and glycidic profile, whereas chia oil had a higher effect on improving the lipid profile. Indeed, supplementation with different fatty acid compositions resulted in specific responses.
\end{abstract}

Keywords: obesity treatment; coconut oil; sunflower oil; chia oil; dietary re-education; lipid and glycemic profile 


\section{Introduction}

Obesity is a chronic disease of multifactorial origin arising from a long-term energy imbalance. It is characterized by fat accumulation in adipose tissues that can cause serious health problems and is often associated with comorbidities such as glucose and lipid metabolism disorders [1]. It is one of the main chronic diseases worldwide, with increasing epidemiological trends. The World Health Organization estimates that by 2025, a total of 700 million people (i.e., $5.4 \%$ of the world's population) will suffer from obesity [2]. Brazil also has an increasing prevalence of obesity (20.8\% of the population is affected), and it predominantly occurs in women ( $24.4 \%$ women vs. $16.8 \%$ men) [3].

Treatments that are currently available have failed to prevent an increase in obesity prevalence [4]. Diet therapy and increased physical activity (PA) [5] reportedly do not result in significant weight loss in the short term, resulting in low adherence to treatment [4]. In contrast, current anti-obesity drugs and surgical treatments have side effects that sometimes outweigh their benefits [6]. Therefore, novel, effective, and safe strategies that are adjuvants to current treatment methods are required. Among these, use of oils with specific fatty acids (FAs) such as medium-chain FAs (MCFAs) and monoand polyunsaturated FAs has demonstrated anti-obesogenic effects $[7,8]$. Some sources of these FAs include coconut oil (Cocos nucifera L.), a source of MCFAs [9]; safflower oil (Carthamus tinctorius), a source of linoleic FA (55-88\%) [10]; and chia oil (Salvia hispanica L.), which contains approximately $60 \%$ $\alpha$-linolenic acid (ALA) [11].

Consumption of the aforementioned oils in the form of capsules has become common for the purpose of weight loss, and they are often used indiscriminately and without nutritional guidance. Capsules are also used in studies for evaluating the physiological effects of specific FAs. In addition to being practical, they mask the taste of oils, protect FAs against oxidation, and make supplementation standardization easier in studies, eliminating possible conformational chemical changes resulting from cooking processes [12].

The physiological role of lipid intake is often a point in question, given its potential beneficial or harmful effects depending on fatty acid composition. Most of the fatty acids present in vegetable oils are associated with health benefits $[13,14]$. However, the effect of vegetable oil supplementation as an adjuvant to the obesity nutritional therapy, particularly in the form of capsules, remains uncertain, with few studies and conflicting results. The determination of the real effects on obesity and comorbidities is necessary for the proper nutritional management of these oils. Here, we aimed to evaluate the supplementation effects of safflower, coconut, and chia oils on anthropometric and biochemical parameters in women with obesity under a hypocaloric diet with standard lifestyle modifications, namely dietary re-education and PA stimulation.

\section{Methods}

\subsection{Participants}

We included women aged between 20 and 40 years who were not menopausal, had a body mass index $(\mathrm{BMI}) \geq 30 \mathrm{~kg} / \mathrm{m}^{2}$ and $\leq 39.9 \mathrm{~kg} / \mathrm{m}^{2}$, and waist circumference (WC) of $>88 \mathrm{~cm} \mathrm{[15],}$ characteristic of abdominal adiposity. They were recruited from the Reference Center on Women's Health, Moreno City, Pernambuco, Brazil. The study protocol was approved by the Research Ethics Committee of the Health Sciences Center of the Federal University of Pernambuco (CAAE 62661416.9.0000.5208) and registered at ClinicalTrials.gov (RBR-36bjsc). All participants signed a written informed consent form. The procedures adopted are in accordance with the Declaration of Helsinki of the World Medical Association.

The exclusion criteria were as follows: pregnancy or smoking; history of cardiovascular, hepatic, renal, neurological, hematological/oncological, endocrine, or gastrointestinal disease; history of eating or psychiatric disorders; allergic reactions; or use of drugs that could interfere with the lipid or glycemic profile. 


\subsection{Study Design and Nutrition Intervention}

A randomized, double-blind, placebo-controlled clinical trial was conducted. Seventy-five participants were randomized and BMI-matched for 8-week oil supplementation into four experimental groups: the coconut oil group ( $\mathrm{CoG}, n=18)$, the safflower oil group ( $\mathrm{SafG}, n=19)$, the chia oil group (ChG, $n=19$ ), and the soybean oil group (placebo group, PG, $n=19$ ). The latter was chosen as the placebo considering that it is used by the majority of the Brazilian population in culinary preparations. A flow chart representing the experimental protocol is presented in Figure 1.

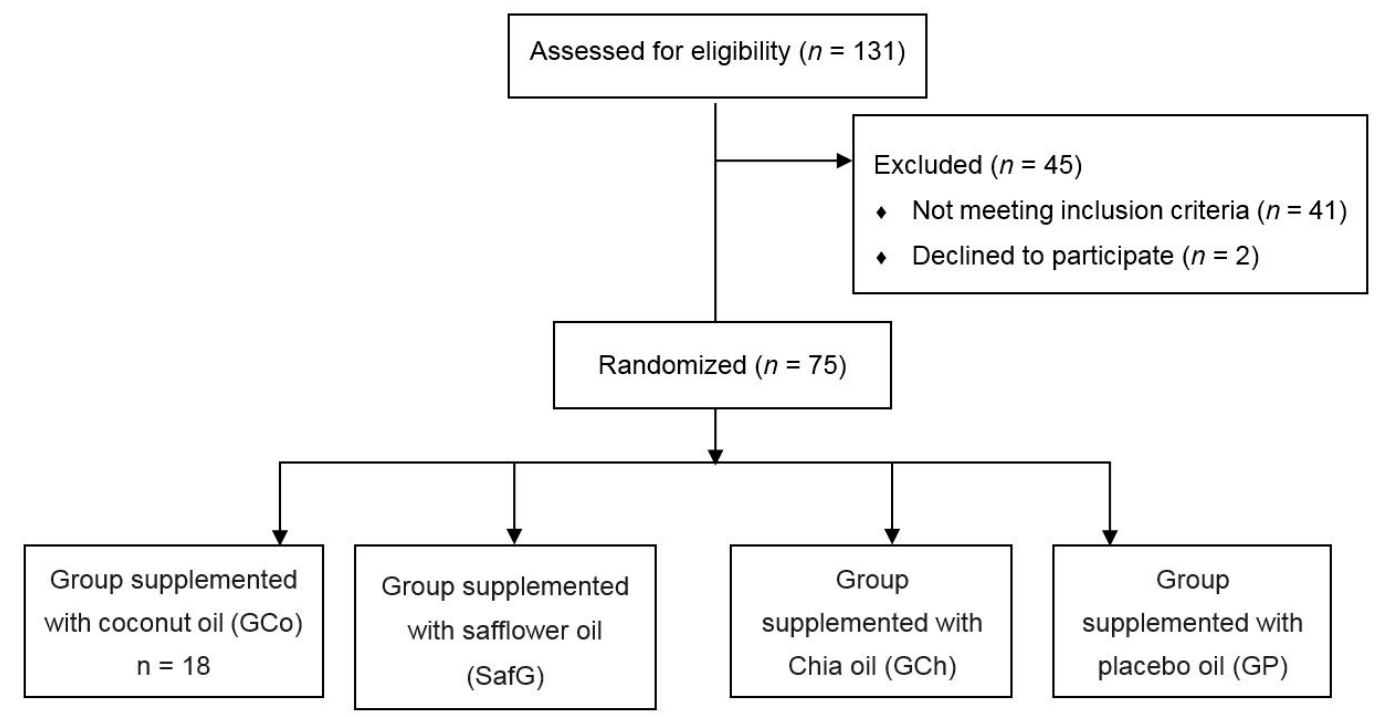

Figure 1. CONSORT diagram of participants representing the experimental groups. Anthropometric assessments, biochemical blood profile, estimated dietary intake, and subjective physical activity were evaluated one week before and one week after the end of the supplementation protocol.

The oils were offered in the form of capsules of similar color, flavor and form, and were supplied by Mosteiro Dévakan Ltd. (São Paulo, Brazil). To ensure quality, centesimal composition analysis of the main FAs was performed using high-performance liquid chromatography in the Food Analysis Laboratory of the Department of Nutrition at the Federal University of Pernambuco (for more details about centesimal composition oils, refer to Supplementary Material (Table S1). All participants were instructed to ingest two capsules ( $1 \mathrm{~g} /$ capsule) $30 \mathrm{~min}$ before main meals $(6 \mathrm{~g} /$ day).

The capsules were filled by a pharmacist who was not affiliated to our research group, in plastic containers with different-colored lids; this codified the oils. The investigators and participants were blinded to the allocation of treatment. The significance of the lid colors was revealed only after the data were collected and analyzed.

The participants were instructed to follow a balanced diet according to the recommendations of Brazilian Association for the Study of Obesity and Metabolic Syndrome-ABESO [5]. They all received guidance from the same nutritionist. An average of $500 \mathrm{kcal}$ of the usual individual energy intake was subtracted, which was evaluated using a three-day food application. In addition, they were advised to perform regular PA in the form of walking for a minimum of $50 \mathrm{~min}$ four times a week [5]. The effectiveness of diet adherence was evaluated through changes in anthropometric parameters at the time of biweekly visits to the nutritionist, during which the oils were distributed and PA stimulation was reinforced.

\subsection{Assessments}

Data on age, schooling, and socioeconomic status [16] were collected at the time of recruitment. Data on anthropometric and biochemical parameters, energy intake, and PA subjective assessment [17] 
were collected one week before the start of dietary intervention and supplementation (T1) and one week after the end of the study (T2).

\subsection{Body Composition}

Weight, height, and WC were evaluated. From these data, BMI, waist-to-height ratio (WHR) [18], and conicity index (CI) were calculated [19]. The percentages of body fat (\%BF), lean mass (\%LM), and water (\%water) were obtained by bioimpedance. In addition, we evaluated the percentage of weight loss, considering a clinically significant loss of $>5 \%$ and / or $10 \%$ [20].

\subsection{Biochemical Evaluation}

Blood samples were collected in the morning after fasting overnight for $8-12 \mathrm{~h}$ in order to quantify total cholesterol, low- and high-density lipoprotein cholesterol (LDLc and HDLc, respectively), triglycerides (Tg), and glycosylated hemoglobin (HbA1c) levels. Mean estimated glycemia (MEG) was obtained using a specific formula from HbA1c $(\mathrm{MEG}=28.7 \times \mathrm{HbA1c}-46.7)$ [21]. From the obtained results, the Tg/HDL ratio [22] was calculated. A detailed description of anthropometric and biochemical parameters is available in Supplementary Material (Table S2).

\section{Statistical Analysis}

Normality was verified through the Shapiro-Wilk test and the equality of variances through the Levene $\mathrm{F}$ test. For parametric data, the paired t-test was used in the comparison between $\mathrm{T} 1$ and T2 times, followed by analysis of variance (two-way ANOVA) with post hoc Tukey's test. For the non-parametric data, the Kruskal-Wallis and Wilcoxon paired tests were used. For evaluation of the size, Cohen's d was used. Pearson's Chi-square test or Fisher's exact test was used when comparing the groups for categorical variables when the condition for Chi-square use was not verified. Statistical analysis was performed using SPSS software (version 23.0 $0^{\circledR}$ ) and MedCalc version 14.8.1. A significance level of $5 \%(p<0.05)$ was utilized.

\section{Results}

It is noteworthy that $70.7 \%$ participants were in social classes B2 and C1,69.3\% were married, and $73.3 \%$ stated that they had completed high school. The mean age of the study population was 34.07 years $(\mathrm{CoG}=33.17 \pm 5.11, \mathrm{SafG}=35.58 \pm 5.23, \mathrm{ChG}=35.00 \pm 5.29$, and $\mathrm{PG}=31.58 \pm 5.85$ years; $p>0.05)$. Socioeconomic data are presented in Table 1.

Table 1. Socioeconomic characterization of participants.

\begin{tabular}{clc}
\hline Variable & $\boldsymbol{n}$ & $\mathbf{\%}$ \\
\hline Socio economic classification & & \\
B1 & 7 & 9.3 \\
B2 1 & 17 & 22.7 \\
C2 & 36 & 48.0 \\
Marital status & 15 & 20.0 \\
Single & & \\
Married & 13 & 17.3 \\
Divorced & 52 & 69.3 \\
Degree of schooling & 10 & 13.3 \\
Primary school & 17 & 22.7 \\
Incomplete primary school & 3 & 4.0 \\
Secondary education & 46 & 61.3 \\
Higher education & 6 & 8.0 \\
Postgraduate & 3 & 4.0 \\
\hline
\end{tabular}


Weight loss (T1 vs. T2) was observed in all groups ( $p<0.001$, Figure 2A). The CoG showed a higher variation between the times $(\Delta \%=-8.54 \pm 2.38, p<0.001$, Cohen's $\mathrm{d}=0.89)$ than the ChG $(\Delta \%=-6.54 \pm 1.41$, Cohen's $\mathrm{d}=0.81)$ and PG $(\Delta \%=-5.00 \pm 1.16$, Cohen's $\mathrm{d}=0.53)$. The SafG $(\Delta \%=-7.19 \pm 1.83$, Cohen's $\mathrm{d}=0.81)$ and ChG showed similar variations, being superior to the PG $(p<0.001)$ (Figure 2B).

A)

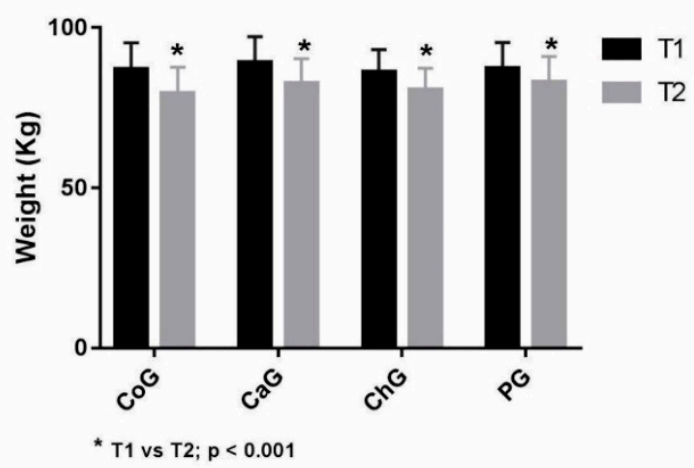

C)

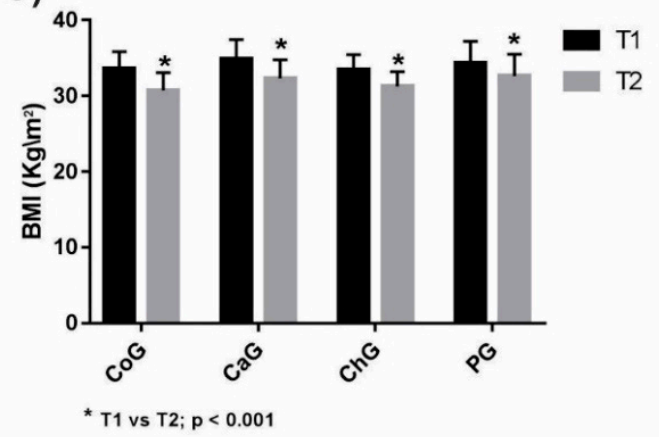

B)

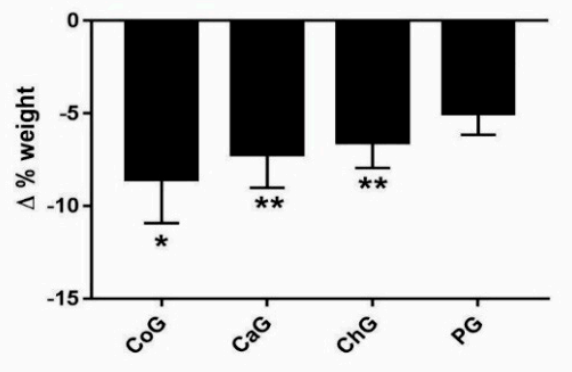

D)

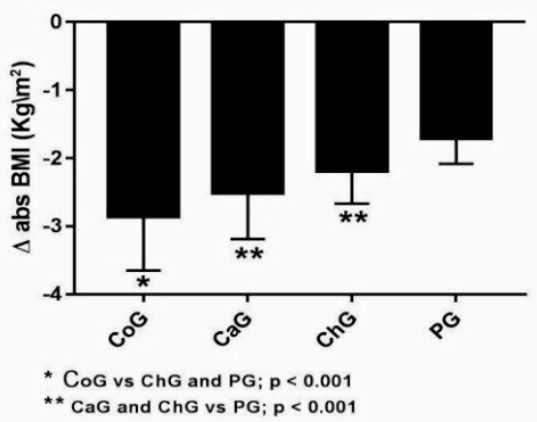

Figure 2. Variation of weight loss and body mass index (BMI). Percentage weight loss (A) and absolute BMI loss (C) (T1 vs. T2). Absolute weight variation (B) and BMI variation (D). Results presented in mean + standard deviation. T1 = Value one week before (T1) and one week after (T2) supplementation protocol; $\Delta=\mathrm{T} 2$ - T1. CoG-Group supplemented with coconut oil; SafG-Group supplemented with safflower oil; ChG—Group supplemented with chia oil; PG—Group supplemented with soybean (placebo) oil.

BMI showed a similar trend to weight. All groups showed a reduction in relation to absolute variation $(\Delta \mathrm{abs})$ (T1 vs. T2, $p<0.001$, Figure $2 \mathrm{C}$ ). The CoG showed a more pronounced variation between the times $(\Delta \mathrm{abs}=-2.86 \pm 0.79, p<0.001$, Cohen's $\mathrm{d}=1.25)$ than the ChG $(\Delta \mathrm{abs}=-2.19 \pm 0.48$, Cohen's $d=1.67)$ and the PG $(\Delta a b s=-1.71 \pm 0.37$, Cohen's $d=0.57)$. The SafG $(\Delta a b s=-2.51 \pm 0.68$, Cohen's d = 0.99) and ChG showed similar and larger variations than those in the PG $(p<0.001$, Figure 2D). Regarding clinical significance, a higher percentage of women had weight loss of $\geq 5 \%$ $(94.4 \%)$ and $10 \%(22.2 \%)$ in the CoG. Table 2 presents the classification of percentage change in weight loss.

A reduction in the anthropometric parameters (T1 vs. T2) WC, WHR, CI, and \%BF (Figure 3A,C,E,G) and an increase in \%LM (Figure 3I) were observed in all experimental groups $(p<0.001)$. The CoG, however, showed higher variations in WC $(\Delta \mathrm{abs}=-6.61 \pm 0.85, p<0.001$, Cohen's $\mathrm{d}=1.09)$, WHR $(\Delta \mathrm{abs}=-0.041 \pm 0.006, p<0.001$, Cohen's $\mathrm{d}=1.33)$, and CI $(\Delta \mathrm{abs}=-0.03 \pm 0.016, p<0.001$, Cohen's d $=0.76)$ relative to the SafG, ChG, and PG. 
A)

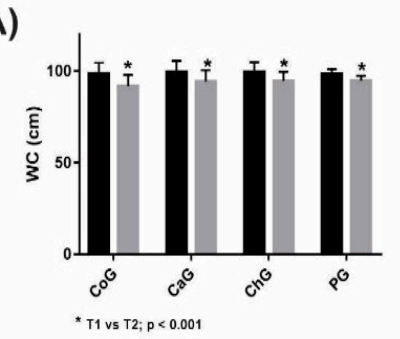

B)

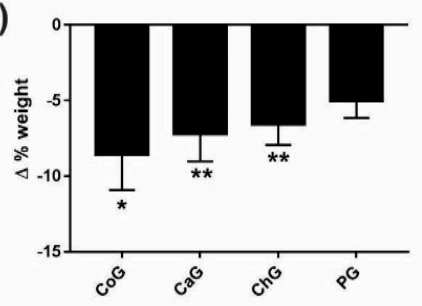

F)

E)

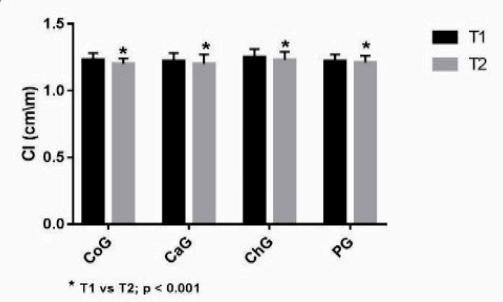

C)

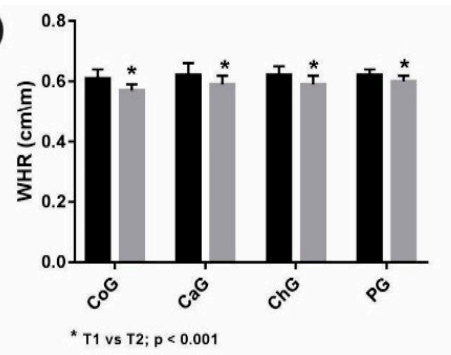

G)

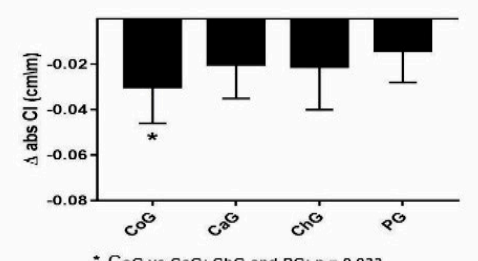

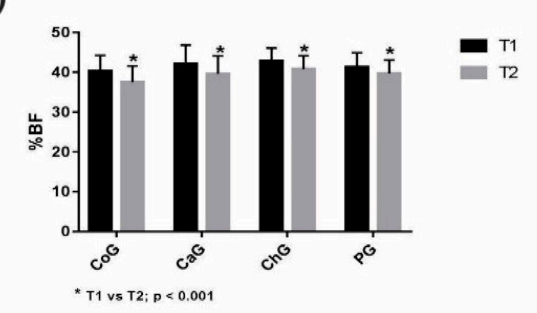

K)

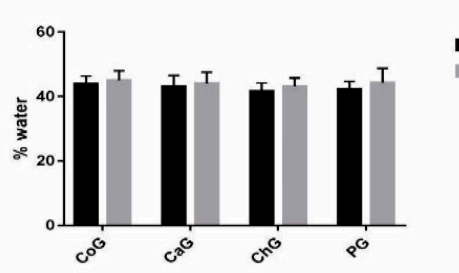

D)

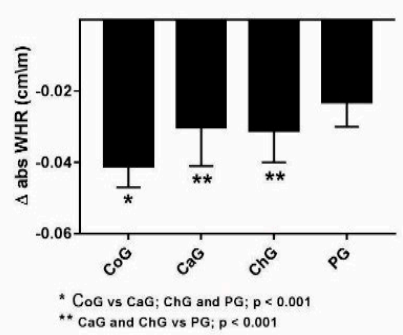

H)

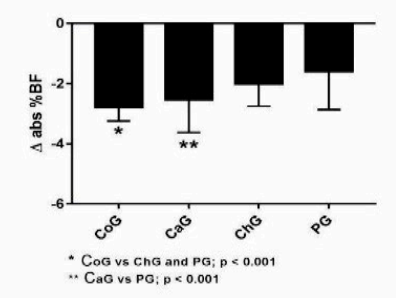

L)

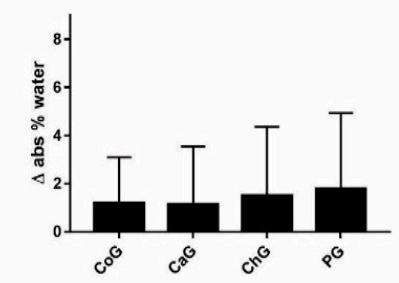

Figure 3. Anthropometric characteristics of participants before (T1) and after (T2) supplementation.T1 vs. T2: WC (A), WHR (C), CI (E),\%BF (G), \%LM (I), and \%water (K). Absolute variation (T1 vs. T2) of WC (B), WHR (D), CI (F), \%BF (H), \%LM (J), and \%water (L). WC-waist circumference; WHR-waist-to-height ratio; $\mathrm{CI}$-conicity index; \%BF—body fat percentage; \%LM—lean mass percentage; \%water-percentage of hydration; CoG—Group supplemented with coconut oil; SafG—Group supplemented with safflower oil; ChG—Group supplemented with chia oil; PG—Group supplemented with soybean (placebo) oil. Results presented as mean + standard deviation (SD). 
Table 2. Percentage of variation in weight loss of the participants.

\begin{tabular}{|c|c|c|c|c|c|c|c|c|c|}
\hline & \multicolumn{8}{|c|}{ Groups } & \multirow{3}{*}{$p$-Value } \\
\hline & \multicolumn{2}{|c|}{$\operatorname{CoG}(n=18)$} & \multicolumn{2}{|c|}{ SafG $(n=19)$} & \multicolumn{2}{|c|}{ ChG $(n=19)$} & \multicolumn{2}{|c|}{ PG $(n=19)$} & \\
\hline & $n$ & $\%$ & $n$ & $\%$ & $n$ & $\%$ & $n$ & $\%$ & \\
\hline \multicolumn{10}{|l|}{ Weight loss \% } \\
\hline$>5 \%$ & 17 & 94.4 & 17 & 89.5 & 17 & 89.5 & 9 & 47.4 & $p=0.002 *$ \\
\hline up to $5 \%$ & 1 & 5.6 & 2 & 10.5 & 2 & 10.5 & 10 & 52.6 & \\
\hline Total & 18 & 100.0 & 19 & 100.0 & 19 & 100.0 & 19 & 100.0 & \\
\hline Weight loss $\%$ & & & & & & & & & $p=0.013$ * \\
\hline$>10 \%$ & 4 & 22.2 & 1 & 5.3 & - & - & - & - & \\
\hline Up to $10 \%$ & 14 & 77.8 & 18 & 94.7 & 19 & 100.0 & 19 & 100.0 & \\
\hline Total & 18 & 100.0 & 19 & 100.0 & 19 & 100.0 & 19 & 100.0 & \\
\hline
\end{tabular}

A higher reduction in \%BF was observed in the CoG $(\Delta \mathrm{abs}=-2.78 \pm 0.46, p<0.001$, Cohen's $\mathrm{d}=0.89$ ) than in the ChG and PG, whereas a higher reduction in \%BF was achieved in the SafG than in the PG $(\Delta$ abs $=-2.53 \pm 1.09, p<0.001$, Cohen's $d=0.79)$. The \%LM increase was higher in the CoG $(\Delta \mathrm{abs}=2.61 \pm 1.40, p<0.001$, Cohen's $\mathrm{d}=0.71)$ than in the ChG and PG. The \%LM increase in the SafG was higher than that in the PG.

The CoG showed higher $\Delta \mathrm{abs}$ for HbA1c $(\Delta \mathrm{abs}=-0.86 \pm 0.28, p<0.001)$ relative to the SafG $(\Delta \mathrm{abs}$ $=-0.49 \pm 0.26, p<0.001$, Cohen's d $=1.28), \mathrm{ChG}(\Delta \mathrm{abs}=-0.53 \pm 0.21, p<0.001$, Cohen's $\mathrm{d}=1.83)$, and PG $(\Delta$ abs $=-0.36 \pm 0.18, p<0.001$, Cohen's d $=1.05) ; \Delta$ abs to MEG was also higher in the CoG $(\Delta$ abs $=-24.71 \pm 8.13, p<0.001$, Cohen's d $=1.65)$ in relation to the SafG $(\Delta$ abs $=-14.20 \pm 7.44$, $p<0.001$, Cohen's d = 1.28), ChG $(\Delta$ abs $=-15.26 \pm 5.98, p<0.001$, Cohen's $d=1.84)$, and PG $(\Delta$ abs $=-10.42 \pm 5.17, p<0.001$, Cohen's d $=1.03)$. Relevant data are presented in Table 3.

Table 3. Blood profile absolute variation of participants before (T1) and after (T2) the supplementation protocol.

\begin{tabular}{|c|c|c|c|c|c|}
\hline & \multicolumn{4}{|c|}{ Groups } & \multirow{2}{*}{$p$-Value } \\
\hline & GCo $(n=18)$ & SafG $(n=19)$ & ChG $(n=19)$ & $\mathrm{GP}(n=19)$ & \\
\hline Biochemical characteristics & Mean \pm SD & Mean \pm SD & Mean \pm SD & Mean \pm SD & \\
\hline \multicolumn{6}{|l|}{ Total cholesterol (TC mg/dL) } \\
\hline $\mathrm{T} 1$ & $215.56 \pm 17.85$ & $200.74 \pm 25.77$ & $232.47 \pm 17.98$ & $214.47 \pm 24.05$ & \\
\hline $\mathrm{T} 2$ & $198.00 \pm 17.60 *$ & $182.95 \pm 19.13$ * & $187.11 \pm 17.04$ * & $195.74 \pm 26.22 *$ & \\
\hline$\Delta$ & $-17.56 \pm 7.70$ & $-17.79 \pm 9.10$ & $-45.36 \pm 8.86^{a}$ & $-18.74 \pm 10.27$ & $p<0.001$ \\
\hline \multicolumn{6}{|l|}{ LDLc (mg/dL) } \\
\hline $\mathrm{T} 1$ & $143.22 \pm 18.78$ & $146 \pm 26.42$ & $166.16 \pm 17.90$ & $142.84 \pm 23.74$ & \\
\hline $\mathrm{T} 2$ & $128.33 \pm 17.72 *$ & $130.63 \pm 24.34$ * & $123.63 \pm 18.24 *$ & $127.47 \pm 23.21$ * & \\
\hline$\Delta$ & $-14.89 \pm 11.53$ & $-15.37 \pm 9.35$ & $-42.53 \pm 22.65^{a}$ & $-15.37 \pm 13.78$ & $p<0.001$ \\
\hline \multicolumn{6}{|l|}{ HDLc (mg/dL) } \\
\hline $\mathrm{T} 1$ & $52.94 \pm 7.94$ & $44.53 \pm 7.19$ & $45.32 \pm 7.17$ & $50.47 \pm 7.61$ & \\
\hline $\mathrm{T} 2$ & $55.61 \pm 6.36^{*}$ & $47.11 \pm 9.82 *$ & $49.05 \pm 5.93 *$ & $49.95 \pm 7.15$ & \\
\hline$\Delta$ & $2.67 \pm 158^{b}$ & $2.58 \pm 2.63$ & $3.73 \pm 1.24^{\mathrm{a}}$ & $0.52 \pm 0.46$ & $p<0.001$ \\
\hline \multicolumn{6}{|l|}{$\operatorname{VLDLc}(\mathrm{mg} / \mathrm{dL})$} \\
\hline $\mathrm{T} 1$ & $21.50 \pm 4.26$ & $18.95 \pm 5.29$ & $23.47 \pm 6.99$ & $21.47 \pm 7.41$ & \\
\hline $\mathrm{T} 2$ & $17.83 \pm 3.17^{*}$ & $15.74 \pm 4.48 *$ & $18.00 \pm 5.08^{*}$ & $20.05 \pm 8.02 *$ & \\
\hline$\Delta$ & $-3.67 \pm 4.56$ & $-3.21 \pm 4.14$ & $-5.47 \pm 7.63$ & $-1.42 \pm 2.76$ & $p=0.421$ \\
\hline \multicolumn{6}{|l|}{ Triglycerides (mg/dL) } \\
\hline $\mathrm{T} 1$ & $130.89 \pm 38.22$ & $129.58 \pm 49.34$ & $137.79 \pm 36.80$ & $132.47 \pm 44.00$ & \\
\hline $\mathrm{T} 2$ & $98.33 \pm 29.09 *$ & $93.95 \pm 36.51 *$ & $88.05 \pm 24.42 *$ & $107.53 \pm 39.18$ * & \\
\hline$\Delta$ & $-32.56 \pm 24.43$ & $-35.63 \pm 23.47$ & $-49.74 \pm 26.36^{a}$ & $-24.94 \pm 28.28$ & $p=0.040$ \\
\hline \multicolumn{6}{|l|}{$\mathrm{Tg} / \mathrm{HDL}$ rate } \\
\hline $\mathrm{T} 1$ & $2.52 \pm 0.75$ & $3.10 \pm 1.77$ & $3.27 \pm 1.07$ & $2.70 \pm 1.05$ & \\
\hline $\mathrm{T} 2$ & $1.78 \pm 0.53 *$ & $2.26 \pm 1.63 *$ & $1.83 \pm 0.58 *$ & $2.24 \pm 1.03 *$ & \\
\hline$\Delta$ & $-0.74 \pm 0.66$ & $-0.84 \pm 0.60$ & $-1.36 \pm 0.88^{a}$ & $-0.46 \pm 0.55$ & $p<0.001$ \\
\hline
\end{tabular}


Table 3. Cont.

\begin{tabular}{|c|c|c|c|c|c|}
\hline & \multicolumn{4}{|c|}{ Groups } & \multirow{2}{*}{$p$-Value } \\
\hline & GCo $(n=18)$ & SafG $(n=19)$ & ChG $(n=19)$ & GP $(n=19)$ & \\
\hline \multicolumn{6}{|c|}{ MEG (mg/dl) } \\
\hline $\mathrm{T} 1$ & $109.56 \pm 7.32$ & $108.28 \pm 13.01$ & $110.7 \pm 9.53$ & $104.2 \pm 11.57$ & \\
\hline $\mathrm{T} 2$ & $84.84 \pm 6.17^{*}$ & $94.08 \pm 8.64 *$ & $95.44 \pm 6.79 *$ & $93.78 \pm 8.31^{*}$ & \\
\hline$\Delta$ & $-24.71 \pm 8.13^{c}$ & $-14.20 \pm 7.44^{d}$ & $-15.26 \pm 5.98^{d}$ & $-10.42 \pm 5.17$ & $p<0.001$ \\
\hline \multicolumn{6}{|c|}{ HbA1C (\%) } \\
\hline $\mathrm{T} 1$ & $5.44 \pm 0.25$ & $5.40 \pm 0.45$ & $5.48 \pm 0.33$ & $5.26 \pm 0.40$ & \\
\hline $\mathrm{T} 2$ & $4.58 \pm 0.21 *$ & $4.91 \pm 0.30 *$ & $4.95 \pm 0.24 *$ & $4.89 \pm 0.29 *$ & \\
\hline$\Delta$ & $-0.86 \pm 0.28^{c}$ & $-0.49 \pm 0.26$ & $-0.53 \pm 0.21$ & $-0.36 \pm 0.18$ & $p<0.001$ \\
\hline
\end{tabular}

Data given as means and standard deviation (SD). $p<0.05$ indicates a significant difference. ${ }^{*}=\mathrm{T} 1 \mathrm{vs.}$ T2; $\mathrm{a}=\mathrm{GCh}$ vs. GCo, GCa, and PL; $\mathrm{b}=\mathrm{GCo}$ and GCa vs. PL; $\mathrm{c}=\mathrm{CCo}$ vs. GCh, GCA, and GP; $\mathrm{d}=\mathrm{GCh}$ and GCa vs. PL. LDLc-low-density lipoprotein cholesterol; HDLc-high-density lipoproteins linked to cholesterol; Tg/HDL—-triglyceride/HDL ratio; HbA1c_-glycosylated hemoglobin; MEG—-mean estimated glycemia; $\Delta=\mathrm{T} 2-\mathrm{T} 1$.

There was a reduction in the total caloric intake (T1 vs. T2) in all experimental groups $(p<0.05)$. Energy variation in the CoG $(\Delta \mathrm{abs}=-612.69 \pm 0.81 .2, p<0.016$, Cohen's $\mathrm{d}=5.81)$ was higher than in $\operatorname{SafG}(\Delta \mathrm{abs}=-500.49 \pm 73.54, p<0.016$, Cohen's d $=1.81), \mathrm{ChG}(\Delta \mathrm{abs}=-532.59 \pm 75.38, p<0.016$, Cohen's $d=1.20)$, and PG ( $\Delta$ abs $=-532.50 \pm 89.84, p<0.016$, Cohen's $d=1.92)$ (Table 4). At the end of the study, all groups showed an increase in the percentage of PA levels (T1 vs. T2), with no significant difference among the groups (Table 5).

Table 4. Food intake variation estimated of participants before (T1) and after (T2) the supplementation protocol.

\begin{tabular}{|c|c|c|c|c|c|}
\hline & \multicolumn{4}{|c|}{ Groups } & \multirow{2}{*}{$p$-Value } \\
\hline & $\operatorname{CoG}(n=18)$ & SafG $(n=19)$ & ChG $(n=19)$ & PG $(n=19)$ & \\
\hline Variables & Mean \pm SD & Mean \pm SD & Mean \pm SD & Mean \pm SD & \\
\hline \multicolumn{6}{|l|}{ Energy (Kcal) } \\
\hline $\mathrm{T} 1$ & $2148.88 \pm 126.51$ & $2080.81 \pm 122.59$ & $2094.59 \pm 94.23$ & $2070.64 \pm 109.96$ & \\
\hline $\mathrm{T} 2$ & $1536.19 \pm 78.60 *$ & $1580.32 \pm 98.69 *$ & $1562 \pm 68.66^{*}$ & $1538.14 \pm 63.82 *$ & \\
\hline$\Delta$ & $-612.69 \pm 81.2 * *$ & $-500.49 \pm 73.54$ & $-532.59 \pm 75.38$ & $-532.50 \pm 89.84$ & $p=0.016$ \\
\hline \multicolumn{6}{|l|}{ Protein (g) } \\
\hline $\mathrm{T} 1$ & $59.71 \pm 6.39$ & $57.81 \pm 5.79$ & $62.31 \pm 8.65$ & $58.68 \pm 6.46$ & \\
\hline $\mathrm{T} 2$ & $62.84 \pm 4.58 *$ & $60.86 \pm 4.96^{*}$ & $63.19 \pm 3.87$ & $61.62 \pm 3.78$ & \\
\hline$\Delta$ & $3.14 \pm 7.56$ & $3.04 \pm 5.75$ & $0.87 \pm 8.15$ & $2.95 \pm 7.33$ & $p=0.735$ \\
\hline \multicolumn{6}{|c|}{ Carbohydrates (g) } \\
\hline $\mathrm{T} 1$ & $354.79 \pm 42.66$ & $349.26 \pm 24.23$ & $352.42 \pm 18.76$ & $345.70 \pm 24.70$ & \\
\hline $\mathrm{T} 2$ & $216.24 \pm 14.83 *$ & $220.28 \pm 15.31 *$ & $223.07 \pm 12.03 *$ & $217.98 \pm 14.32 *$ & \\
\hline$\Delta$ & $-138.55 \pm 41.19$ & $-128.98 \pm 20.00$ & $-129.34 \pm 17.56$ & $-127.71 \pm 28.19$ & $p=0.375$ \\
\hline \multicolumn{6}{|l|}{ Lipids (g) } \\
\hline $\mathrm{T} 1$ & $54.55 \pm 11.11$ & $50.28 \pm 7.18$ & $48.41 \pm 6.68$ & $50.35 \pm 6.91$ & \\
\hline $\mathrm{T} 2$ & $51.65 \pm 3.81$ & $48.64 \pm 4.26$ & $46.33 \pm 3.59$ & $48.63 \pm 3.28 *$ & \\
\hline$\Delta$ & $-2.9 \pm 6.21$ & $1-1.69 \pm 5.89$ & $-2.08 \pm 5.33$ & $-1.71 \pm 6.44$ & $p=0.116$ \\
\hline \multicolumn{6}{|l|}{ Fiber (g) } \\
\hline $\mathrm{T} 1$ & $11.48 \pm 1.98$ & $12.14 \pm 1.84$ & $12.36 \pm 1.50$ & $12.20 \pm 1.68$ & \\
\hline $\mathrm{T} 2$ & $25.94 \pm 2.86^{*}$ & $25.71 \pm 2.26^{*}$ & $24.63 \pm 3.07 *$ & $26.28 \pm 2.86^{*}$ & \\
\hline$\Delta$ & $14.46 \pm 3.59$ & $13.57 \pm 2.56$ & $12.26 \pm 2.44$ & $14.08 \pm 2.18$ & $p=0.109$ \\
\hline
\end{tabular}

Data given as means and standard deviation (SD). $p<0.05$ indicates a different significance: ${ }^{*}=\mathrm{T} 1 \mathrm{vs}$. $\mathrm{T} 2$; ${ }^{* *}=\mathrm{CCo}$ vs. GCh, GCA, and GP. CoG_-Group supplemented with coconut oil; SafG—Group supplemented with safflower oil; ChG-Group supplemented with chia oil; PG_Group supplemented with soybean (placebo) oil. $\Delta=\mathrm{T} 1-\mathrm{T} 2$. 
Table 5. Level of physical activity of the participants before (T1) and after (T2) the study.

\begin{tabular}{|c|c|c|c|c|c|c|c|c|c|c|c|}
\hline \multirow{3}{*}{ Classification } & \multicolumn{10}{|c|}{ Groups } & \multirow{3}{*}{$p$-Value } \\
\hline & \multicolumn{2}{|c|}{ CoG $(n=18)$} & \multicolumn{2}{|c|}{ SafG $(n=19)$} & \multicolumn{2}{|c|}{ ChG $(n=19)$} & \multicolumn{2}{|c|}{ PG $(n=19)$} & \multicolumn{2}{|c|}{ Total } & \\
\hline & $n$ & $\%$ & $n$ & $\%$ & $n$ & $\%$ & $n$ & $\%$ & $n$ & $\%$ & \\
\hline Total & 18 & 100.0 & 19 & 100.0 & 19 & 100.0 & 19 & 100.0 & 75 & 100.0 & \\
\hline $\mathrm{T} 1$ & & & & & & & & & & & $p=0.031$ * \\
\hline Sedentary & 14 & 77.8 & 15 & 78.9 & 16 & 84.2 & 19 & 100.0 & 63 & 84.0 & \\
\hline Active & 4 & 22.2 & 4 & 32.1 & 3 & 15.8 & - & - & 12 & 16.0 & \\
\hline T2 & & & & & & & & & & & $p=0.278$ \\
\hline Sedentary & 7 & 38.9 & 6 & 31.6 & 5 & 26.3 & 19 & 47.4 & 45 & 60.0 & \\
\hline Active & 11 & 61.1 & 13 & 68.4 & 14 & 73.7 & 10 & 52.6 & 30 & 40.0 & \\
\hline$p$-value & \multicolumn{2}{|c|}{$p=0.044$} & \multicolumn{2}{|c|}{$p=0.041$} & \multicolumn{2}{|c|}{$p=0.021$} & \multicolumn{2}{|c|}{$* *$} & \multicolumn{2}{|c|}{$p<0.001 *$} & \\
\hline
\end{tabular}

Subjective evaluation of the participants' physical activity before (start) and after (last) the study period. ${ }^{*}=p<0.05$. ** = Not determined due to the difference in the number of response categories between the two evaluations. CoG-Group supplemented with coconut oil; SafG-Group supplemented with safflower oil; ChG-Group supplemented with chia oil; PG—Group supplemented with soybean (placebo) oil.

\section{Discussion}

Eight weeks of daily supplementation were sufficient to observe different supplementationdependent effects on anthropometric and biochemical parameters according to the different oils used in the present study when this was associated with a hypocaloric diet and lifestyle modifications. With regard to coconut oil supplementation, we observed a higher adjuvant effect on weight loss and \%BF, with an emphasis on the reduction of anthropometric parameters associated with abdominal adiposity. Our findings are consistent with those reported by Assunção et al. [23] and Cardoso et al. [24], who reported a reduction in WC that was associated with a significant increase in HDLc after coconut oil supplementation as compared to placebo oil (a source of long-chain FAs (LCFAs)) supplementation in obese women. Our findings regarding the reduction in WHR and CI reinforce the potential effects of coconut oil in causing a decrease in abdominal adiposity.

Unlike LCFAs, MCFAs do not require chylomicron transport via the lymphatic system to reach their target tissues, thereby favoring hepatic metabolism and mitochondrial oxidation [25,26]. These FAs would still be favored because they do not depend on carnitine palmitoyltransferase-1, which is a key enzyme facilitating the entry of FAs into the mitochondria for further oxidation [26]. Therefore, the intake of oils containing MCFA should result in increased thermogenesis and fat oxidation with a consequent loss of fat mass, potentially aiding in stimulating weight loss [26].

Because coconut oil is a source of saturated FAs, an important reason behind the debate involves the possible adverse effects of coconut oil on the lipid profile and consequent risk of cardiovascular disease. Although the literature has reported conflicting results [23,24,27], women supplemented with coconut oil did not show any adverse changes in their lipid profile in this present study. On the contrary, they experienced beneficial effects, such as an increased HDLc levels and decreased Tg/HDL ratio as compared to the PG.

Our findings are in agreement with those of Assunção et al. [23], Cardoso et al. [24], and Chinwong et al. [28], who reported no deleterious effects and increased HDLc levels in women that took coconut oil supplements. The epidemiological evidence from the populations consuming substantial amounts of coconut oil reinforces the idea of the lack of negative effects on cardiovascular health [29]. In a systematic review, Eryres et al. [25] did not find evidence of any adverse effects of consuming coconut oil on the lipid profile. Furthermore, in a 28-day study involving postmenopausal women without nutritional monitoring, Harrys et al. [27] compared the impact of coconut oil supplementation with that of safflower oil supplementation and reported that the former significantly increased TC LDLc, and HDLc levels and decreased Tg levels. Therefore, the inconsistencies observed between studies are justified by the nutritionally different context in which they are performed and the period during which supplementation is introduced. 
The positive effect of coconut oil supplementation on the glycemic profile in the present study is consistent with the findings from studies in rats [30,31], which reported an improvement in glycemia and insulin response in individuals with obesity when supplemented with MCFAs. This could be due to the effect of polyphenolic anti-oxidants in coconut oil, such as caffeic acid, ferulic acid, syringic acid, catechin, and epigallocatechin, which are known to have anti-diabetic and insulin-sensitizing effects [32,33]. The glycemic response may have also contributed to the higher weight loss observed in the CoG, with weight loss also improving glycemic parameters. Thus, this generates positive feedback.

Although the total caloric intake was similar among the groups, the higher observed decrease in the CoG may have contributed to the higher weight loss observed. As a source of fat during breakfast, coconut oil has been reported to increase satiety in obesity woman [34]. However, Kingela et al. [35] did not report such an increase upon the use of coconut oil compared to isolated MCFAs. Deol et al. observed more obesogenic and diabetogenic effects when using soybean oil compared to coconut oil in mice [36].

The SafG and (to a lesser degree) the ChG showed beneficial effects in relation to weight loss. These effects could be because polyunsaturated LCFAs, such as linoleic and linolenic acids, play important roles as peroxisome proliferator-activated receptor $\alpha$ ligands, inhibiting the differentiation of preadipocytes into mature adipose tissue cells. Polyunsaturated LCFAs also suppress the activity of sterol regulatory element-binding protein-1c and the expression of carbohydrate response element-binding protein, which are transcription factors that induce lipogenesis. This potentially implies a gene expression profile that favors lipolysis $[7,8]$.

In its metabolic pathway, linoleic acid is converted to arachidonic acid (AA), which has contradictory roles in relation to adipogenesis. According to Madsen et al. [37], such contradictions result from the fact that the physiological effect of AA on adipocyte differentiation is related to cAMP signaling, which plays a key role in controlling prostaglandin production. A high glucagon/insulin ratio, which was caused by a decrease in carbohydrate supply and an increase in protein intake observed in the study population, improves cAMP-dependent signaling pathways, resulting in the production of anti-adipogenic prostaglandins that function in the adaptive reactions of cyclooxygenases. In this context, AA action would result in increased lipolysis of white adipose tissue. Thus, the dietary context in which supplementation with safflower oil was introduced may be a determinant for AA action [37]. AA was still associated with the browning of adipose tissue in rats, which protects against the deleterious effects of obesity [38]. In addition, the active components of safflower oil may inhibit preadipocyte proliferation and adipogenesis in rats, potentiating the expression of hormone-sensitive lipase and inhibiting the action of lipoprotein lipase. This results in a lipolytic state that favors weight loss $[39,40]$.

In this study, the ChG showed predominance over other groups with respect to a decrease in CT, LDLc, and Tg levels and an increase in the HDLc level compared to that in the PG, which contributes to a decrease in cardiovascular risk. The type of dietary FA may modulate the amount of intracellular plasma cholesterol. During its metabolic pathway, the ALA present in chia oil is converted to eicosapentaenoic acid (EPA, C22:5) and docosahexaenoic acid (DHA, C22:6) [41]. EPA and DHA are associated with beneficial changes in lipid metabolism, which may alter serum cholesterol concentrations by reducing Tg levels and increasing plasma HDLc levels $[7,8,11,40,42]$.

Few studies have evaluated the specific effects of chia oil supplementation as a source of ALA on biochemical parameters, particularly in humans. Consistent with our results, Santos-Lopez et al. observed that chia oil supplementation in elderly rats reduced cholesterol [43]. In a cross-sectional study conducted by Dittrich et al. involving humans with hypertriglyceridemia, a decrease in Tg levels was reported after supplementation of oil containing ALA [44]. Similarly, Mirfatabi et al. [45] reported a reduction in serum Tg levels in hemodialysis patients who consumed flaxseed oil, which is another important source of ALA. In addition, Zhao et al. [46] reported a decrease in LDLc, HDLc, and Tg levels, with increased dietary amounts of ALA in a study involving hypercholesterolemic men. In a 
recent meta-analysis, Maki and Dicklin found evidence supporting the beneficial effects of consuming chia oil in terms of the lipid profile [47].

Dietary re-education and lifestyle modifications are important for anti-obesity treatment, and should lead to an improvement in anthropometric and biochemical parameters [48]. Nutritional orientation, resulting in changes in dietary habits, was defined by increased protein and fiber intake but decreased carbohydrate intake in addition to an increase in PA, possibly playing a role in determining the results obtained in this study.

In conclusion, our findings suggest that there are beneficial supplementation-dependent effects of vegetable oils with varying fatty acid compositions on anthropometric and biochemical parameters in obese women who also changed to a hypocaloric diet with further lifestyle modifications. Coconut oil is potentially more effective for treating obesity as it encourages a loss of abdominal adiposity and an improvement in glycemic parameters without any undesirable alterations in the lipid profile, while chia oil seems to have a more pronounced effect in improving lipid parameters. The other biochemical compounds present in the oils may have influenced the results obtained. Nutritional monitoring and PA stimulation were fundamental in obtaining the desired results, contraindicating the current indiscriminate use of supplements without any nutritional guidance. The findings of this study provide support for current recommendations for the use of such supplements in obese people. Further intervention studies with a longer duration need to be conducted in order to better evaluate the effects of supplementation with the above-mentioned oils.

Supplementary Materials: The following are available online at http:/ /www.mdpi.com/2072-6643/10/7/932/s1, Table S1: Centesimal Composition of the oils used in the study. Table S2: Description of anthropometric and biochemical evaluations.

Author Contributions: L.O.-d.-L., S.L.d.S., E.M.C.S., M.C.d.S., and T.G.d.N., had full access to all of the data in the study and take responsibility for the integrity of the data. R.F.d.S. and P.A.d.L.S.S. take responsibility for the accuracy of the data analysis; L.O.-d.-L., S.L.d.S., and E.M.C.S. proposed the study concept and designed the study; R.F.d.S. and P.A.d.L.S.S. analyzed the data; L.O.-d.-L., S.L.d.S., E.M.C.S., R.F.d.S., R.J.B.M., and L.d.S.O., contributed to the interpretation of the data and provided a critical review of the manuscript; L.O.-d.-L., were primarily responsible for drafting the manuscript. R.F.d.S. provided the graphical abstract. L.O.-d.-L. was responsible for project administration. All authors revised, editing and approved the final manuscript.

Funding: This study received financial support from Federal University of Pernambuco and costs were borne by the authors.

Acknowledgments: The authors wish to thank the participants and Professor Sebastião Camilo M. Filho for validating the oils used in this study.

Conflicts of Interest: The authors declare that there is no conflict of interest.

\section{References}

1. Egger, G.; Dixon, J. Beyond obesity and lifestyle: A review of 21st century chronic disease determinants. Biomed. Res. Int. 2014, 2014, 1-12. [CrossRef] [PubMed]

2. World Health Organization/Food and Agriculture Organization. Diet, Nutrition and the Prevention of Chronic Diseases; Report of a Joint WHO/FAO Expert Consultation; WHO: Geneva, Switzerland, 2013.

3. Instituto Brasileiro de Geografia e Estatística. Pesquisa Nacional de Saúde 2013: Percepção do estado de saúde, estilos de vida e doenças crônicas-Brasil, Grandes Regiões e Unidades da Federação; Instituto Brasileiro de Geografia e Estatística: Rio de Janeiro, Brazil, 2014.

4. Frood, S.; Johnston, L.M.; Matteson, C.L.; Finegood, D.T. Obesity, complexity, and the role of the health system. Curr. Obes. Rep. 2013, 2, 320-326. [CrossRef] [PubMed]

5. ABESO. Diretrizes Brasileiras de Obesidade; ABESO: São Paulo, Brazil, 2016; pp. 75-91.

6. Yanovski, S.Z.; Yanovski, J.A. Drugs for the treatment of obesity-Reply. JAMA Intern. Med. 2014, 174, 1415-1416. [CrossRef] [PubMed]

7. Nakamura, M.T.; Yudell, B.E.; Loor, J.J. Regulation of energy metabolism by long-chain fatty acids. Prog. Lipid Res. 2014, 53, 124-144. [CrossRef] [PubMed]

8. Rodríguez-Cruz, M.; Serna, D.S. Nutrigenomics of $\omega-3$ fatty acids: Regulators of the master transcription factors. Nutrition 2017, 41, 90-96. [CrossRef] [PubMed] 
9. Fernando, W.M.; Martins, I.J.; Goozee, K.G.; Brennan, C.S.; Jayasena, V.; Martins, R.N. The role of dietary coconut for the prevention and treatment of Alzheimer's disease: Potential mechanisms of action. Br. J. Nutr. 2015, 114, 1-14. [CrossRef] [PubMed]

10. Vousoughkia, M.; Hossainchi Ghareaghag, L.; Ghavami, M.; Gharachorloo, M.; Delkhosh, B. Evaluation of oil content and fatty acid composition in seeds of different genotypes of safflower (Carthamus Tinctorius L.). Int. J. Agric. Sci. Res. 2011, 2, 59-66.

11. Ullah, R.; Nadeem, M.; Khalique, A.; Imran, M.; Mehmood, S.; Javid, A.; Hussain, J. Nutritional and therapeutic perspectives of Chia (Salviahispanica L.): A review. J. Food Sci. Technol. 2016, 53, 1750-1758. [CrossRef] [PubMed]

12. Jamilian, M.; Samimi, M.; Mirhosseini, N.; Afshar Ebrahimi, F.; Aghadavod, E.; Taghizadeh, M.; Asemi, Z. A Randomized Double-Blinded, Placebo-Controlled Trial Investigating the Effect of Fish Oil Supplementation on Gene Expression Related to Insulin Action, Blood Lipids, and Inflammation in Gestational Diabetes Mellitus-Fish Oil Supplementation and Gestational Diabetes. Nutrients 2018, 10, 163.

13. Clevenger, H.C.; Stevenson, J.L.; Cooper, J.A. Metabolic responses to dietary fatty acids in obese women. Physiol. Behav. 2015, 139, 73-79. [CrossRef] [PubMed]

14. Raatz, S.K.; Conrad, Z.; Johnson, L.K.; Picklo, M.J.; Jahns, L. Relationship of the Reported Intakes of Fat and Fatty Acids to Body Weight in US Adults. Nutrients 2017, 9, 438. [CrossRef] [PubMed]

15. World Health Organization (WHO). Waist Circumference and Waist-Hip Ratio; Report of a WHO Expert Consultation; WHO: Geneva, Switzerland, 2008.

16. Associação Brasileira de Empresas de Pesquisa (ABEP). Critério Padrão de Classificação Econômica Brasil; ABEP: São Paulo, Brazil, 2015.

17. Matsudo, S.; Araújo, T.; Matsudo, V.; Andrade, D.; Andrade, E.; Oliveira, L.C.; Braggion, G. Questionário Internacional de Atividade Física (IPAQ): Estudo de validade e reprodutibilidade no Brasil. Rev. Bras. Ativ. Fís. Saúde 2001, 6, 5-12.

18. Haun, D.R.; Pitanga, F.J.G.; Lessa, I. Razão Cintura/estatura comparado a Outros indicadores antropométricos de Obesidade como preditor de Risco coronariano elevado. Rev. Assoc. Med. Bras. 2009, 55, 705-711. [CrossRef] [PubMed]

19. Valdez, R. A simple model-based index of abdominal adiposity. J. Clin. Epidemiol. 1991, 44, 955-956. [CrossRef]

20. Ryan, D.H.; Yockey, S.R. Weight Loss and Improvement in Comorbidity: Differences at 5\%, 10\%, 15\%, and Over. Curr. Obes. Rep. 2017, 6, 187-194. [CrossRef] [PubMed]

21. Nathan, D.M.; Kuenen, J.; Borg, R.; Zheng, H.; Schoenfeld, D.; Heine, R.J. Translationg the A1C assay into estimated average glucose values. Diabetes Care 2008, 31, 1473-1478. [CrossRef] [PubMed]

22. Da Luz, P.L.; Favarato, D.; Faria-Neto, J.R.; Lemos, P.; Chagas, A.C.P. High ratio of triglycerides to HDL cholesterol predicts extensive coronary disease. Clinics 2008, 63, 427-432. [PubMed]

23. Assuncão, M.L.; Ferreira, H.S.; Dos Santos, A.F.; Cabral, C.R., Jr.; Florêncio, T.T.M.M.T. Effects of dietary coconut oil on the biochemical and anthropometric profiles of women presenting abdominal obesity. Lipids 2009, 44, 593-601. [CrossRef] [PubMed]

24. Cardoso, D.A.; Moreira, A.S.; de Oliveira, G.M.; Raggio Luiz, R.; Rosa, G. A coconut extra virgin oil-rich diet increases hdl cholesterol and decreases waist circumference and body mass in coronary artery disease patients. Nutr. Hosp. 2015, 32, 2144-2152. [PubMed]

25. Eyres, L.; Eyres, M.F.; Chisholm, A.; Brown, RC. Coconut oil Consumption and cardiovascular risk factors in humans. Nutr. Rev. 2016, 74, 267-280. [CrossRef] [PubMed]

26. Mumme, K.; Stonehouse, W. Effects of medium-chain triglycerides on weight loss and body composition: A meta-analysis of randomized controlled trials. J. Acad. Nutr. Diet. 2015, 115, 249-263. [CrossRef] [PubMed]

27. Harris, M.; Hutchins, A.; Fryda, L. The Impact of Virgin Coconut Oil and High-Oleic Safflower Oil on Body Composition, Lipids, and Inflammatory Markers in Postmenopausal Women. J. Med. Food 2017, 20, 345-351. [CrossRef] [PubMed]

28. Chinwong, S.; Chinwong, D.; Mangklabruks, A. Daily Consumption of Virgin Coconut Oil Increases High-Density Lipoprotein Cholesterol Levels in Healthy Volunteers: A Randomized Crossover Trial. Evid.-Based Complement. Altern. Med. 2017, 2017, 1-8. [CrossRef] [PubMed] 
29. Lipoeto, N.I.; Agus, Z.; Oenzil, F.; Wahlqvist, M.L.; Wattanapenpaiboon, N. Dietary intake and the risk of coronary heart disease among the coconut-consuming Minangkabau in West Sumatra, Indonesia. Asia Pac. J. Clin. Nutr. 2004, 13, 377-384. [PubMed]

30. Geng, S.; Zhu, W.; Xie, C.; Li, X.; Wu, J.; Liang, Z.; Xie, W.; Zhu, J.; Huang, C.; Zhu, M.; et al. Medium-chain triglyceride ameliorates insulin resistance and inflammation in high fat diet-induced obese mice. Eur. J. Nutr. 2016, 55, 931-940. [CrossRef] [PubMed]

31. Narayanankutty, A.; Mukesh, R.K.; Ayoob, S.K.; Ramavarma, S.K.; Suseela, I.M.; Manalil, J.J.; Kuzhivelil, B.T.; Raghavamenon, A.C. Virgin coconut oil maintains redox status and improves glycemic conditions in high fructose fed rats. J. Food Sci. Technol. 2016, 53, 895-901. [CrossRef] [PubMed]

32. Marina, A.M.; Man, Y.B.; Nazimah, S.A.; Amin, I. Antioxidant capacity and phenolic acids of virgin coconut oil. Int. J. Food Sci. Nutr. 2008, 2, 114-123. [CrossRef] [PubMed]

33. Srinivasan, S.; Muthukumaran, J.; Muruganathan, U.; Venkatesan, R.S.; Jalaludeen, A.M. Antihyperglycemic effect of syringic acid on attenuating the key enzymes of carbohydrate metabolism in experimental diabetic rats. Biomed. Prev. Nutr. 2014, 4, 595-602. [CrossRef]

34. Valente, F.X.; Cândido, F.G.; Lopes, L.L.; Dias, D.M.; Carvalho, S.D.; Pereira, P.F.; Bressan, J. Effects of coconut oil consumption on energy metabolism, cardiometabolic risk markers, and appetitive responses in women with excess body fat. Eur. J. Nutr. 2018, 57, 1627-1637. [CrossRef] [PubMed]

35. Kinsella, R.; Maher, T.; Clegg, M.E. Coconut oil has less satiating properties than medium chain triglyceride oil. Physiol. Behav. 2017, 179, 422-426. [CrossRef] [PubMed]

36. Deol, P.; Evans, J.R.; Dhahbi, J.; Chellappa, K.; Han, D.S.; Spindler, S.; Sladek, F.M. Soybean Oil Is More Obesogenic and Diabetogenic than Coconut Oil and Fructose in Mouse: Potential Role for the Liver. PLoS ONE 2015, 10, e0132672. [CrossRef] [PubMed]

37. Madsen, L.; Pedersen, L.M.; Liaset, B.; Ma, T.; Petersen, R.K.; van den Berg, S.; Pan, J.; Müller-Decker, K.; Dülsner, E.D.; Kleemann, R.; et al. cAMP-dependent signaling regulates the adipogenic effect of n-6 polyunsaturated fatty acids. J. Biol. Chem. 2008, 283, 7196-7205. [CrossRef] [PubMed]

38. Mao, L.; Lei, J.; Schoemaker, M.H.; Ma, B.; Zhong, Y.; Lambers, T.T.; Van Tol, E.A.F.; Zhou, Y.; Nie, T.; Wu, D. Long-chain polyunsaturated fatty acids and extensively hydrolyzed casein-induced browning in a Ucp-1 reporter mouse model of obesity. Food Funct. 2018, 25, 2362-7233. [CrossRef] [PubMed]

39. Yu, S.Y.; Lee, Y.J.; Kim, J.D.; Kang, S.N.; Lee, S.K.; Jang, J.Y.; Lee, H.K.; Lim, J.H.; Lee, O.H. Phenolic Composition, Antioxidant Activity and Anti-Adipogenic Effect of Hot Water Extract from Safflower (CarthamustinctoriusL.) Seed. Nutrients 2013, 5, 4894-4907. [CrossRef] [PubMed]

40. Zhu, H.; Wang, X.; Pan, H.; Dai, Y.; Li, N.; Wang, L.; Yang, H.; Gong, F. The Mechanism by Which Safflower Yellow Decreases Body Fat Mass and Improves Insulin Sensitivity in HFD-Induced Obese Mice. Front. Pharmacol. 2016, 7, 127. [CrossRef] [PubMed]

41. Baker, E.J.; Miles, E.A.; Burdge, G.C.; Yaqoob, P.; Calder, P.C. Metabolism and functional effects of plant-derived omega-3 fatty acids in humans. Prog. Lipid Res. 2016, 64, 30-56. [CrossRef] [PubMed]

42. Jiménez-Gómez, Y.; Marín, C.; Peérez-Martínez, P.; Hartwich, J.; Malczewska-Malec, M.; Golabek, I.; Kiec-Wilk, B.; Cruz-Teno, C.; Rodríguez, F.; Gómez, P.; et al. A low-fat, high-complex carbohydrate diet supplemented with long-chain (n-3) fatty acids alters the postprandial lipoprotein profile in patients with metabolic syndrome. J. Nutr. 2010, 140, 1595-1601. [CrossRef] [PubMed]

43. Santos-López, J.A.; Garcimartín, A.; López-Oliva, M.E.; Bautista-Ávila, M.; González-Muñoz, M.J.; Bastida, S.; Benedí, J.; Sánchez-Muniz, F.J. Chia Oil-Enriched Restructured Pork Effects on Oxidative and Inflammatory Status of Aged Rats Fed High Cholesterol/High Fat Diets. J. Med. Food 2017, 20, 526-534. [CrossRef] [PubMed]

44. Dittrich, M.; Jahreis, G.; Bothor, K.; Drechsel, C.; Kiehntopf, M.; Blüher, M.; Dawczynski, C. Benefits of foods supplemented with vegetable oils rich in alpha-linolenic, stearidonic or docosahexaenoic acid in hypertriglyceridemic subjects: A double-blind, randomized, controlled trail. Eur. J. Nutr. 2014, 54, 881-893. [CrossRef] [PubMed]

45. Mirfatahi, M.; Tabibi, H.; Nasrollahi, A.; Hedayati, M. Effects of Flaxseed Oil on Serum Lipids and Lipoproteins in Hemodialysis Patients: A Randomized Controlled Trial. Iran. J. Kidney Dis. 2016, 10, 405-412. [PubMed] 
46. Zhao, G.; Etherton, T.D.; Martin, K.R.; West, S.G.; Gillies, P.J.; Kris-Etherton, P.M. Dietary alpha-linolenic acid reduces inflammatory and lipid cardiovascular risk factors in hypercholesterolemic men and women. J. Nutr. 2004, 134, 2991-2997. [CrossRef] [PubMed]

47. Maki, K.C.; Dicklin, M.R. Omega-3 Fatty Acid Supplementation and Cardiovascular Disease Risk: Glass Half Full or Time to Nail the Coffin Shut? Nutrients 2018, 10, 864. [CrossRef] [PubMed]

48. Pearl, R.L.; Wadden, T.A.; Tronieri, J.S.; Berkowitz, R.I.; Chao, A.M.; Alamuddin, N.; Leonard, S.M.; Carvajal, R.; Bakizada, Z.M.; Pinkasavage, E.; et al. Short- and Long-Term Changes in Health-Related Quality of Life with Weight Loss: Results from a Randomized Controlled Trial. Obesity 2018, 26, 985-991. [CrossRef] [PubMed]

(C) 2018 by the authors. Licensee MDPI, Basel, Switzerland. This article is an open access article distributed under the terms and conditions of the Creative Commons Attribution (CC BY) license (http:/ / creativecommons.org/licenses/by/4.0/). 